\title{
Article \\ Developing Evaluation Framework for Intelligent Transport System on Public Transportation in Bangkok Metropolitan Regions Using Fuzzy AHP
}

\author{
Aoonrot Choosakun (D) and Chunho Yeom * (D) \\ International School of Urban Science, University of Seoul, Seoulsiripdaero 163, Dongdaemun-gu, \\ Seoul 02504, Korea; aroonrot@gmail.com \\ * Correspondence: chunhoy7@uos.ac.kr
}

Citation: Choosakun, A.; Yeom, C. Developing Evaluation Framework for Intelligent Transport System on Public Transportation in Bangkok Metropolitan Regions Using Fuzzy AHP. Infrastructures 2021, 6, 182. https://doi.org/10.3390/ infrastructures6120182

Academic Editor: Benedetto Barabino

Received: 25 November 2021

Accepted: 17 December 2021

Published: 20 December 2021

Publisher's Note: MDPI stays neutral with regard to jurisdictional claims in published maps and institutional affiliations.

Copyright: (C) 2021 by the authors. Licensee MDPI, Basel, Switzerland. This article is an open access article distributed under the terms and conditions of the Creative Commons Attribution (CC BY) license (https:// creativecommons.org/licenses/by/ $4.0 /)$.

\begin{abstract}
Public transportation has been encouraged as a significant solution to overcome traffic congestion. An advanced technology, known as advanced public transport system (APTS), was introduced to enhance the effectiveness of public transportation. To support appropriate decisions on selecting application development, significant indicators representing the impacts of the proposed projects are highlighted. This study aims to determine the desirable indicators of developing APTS to achieve smart mobility using the fuzzy Analytical Hierarchy Process (fuzzy AHP) method and allocating weights to each indicator. The perception of a group of intelligent transport system (ITS) experts from three sectors in the Bangkok Metropolitan Regions (BMR) was examined to conduct a fuzzy AHP pairwise comparison. The ranking of 21 indicators categorized within six dimensions in accordance with the specific ITS master plan relating to APTS development is presented. The result presented that the safety dimension obtained the highest rank, and the three most important weight indicators are traffic accident reduction relating to public transportation, smart public transport network density and waiting time for public transportation. In addition, the perspectives towards APTS development and assessment framework development in BMR is highlighted to revise impediment of regulation and encourage integration among stakeholders. Then, the approaches of the APTS evaluation framework in BMR are proposed.
\end{abstract}

Keywords: intelligent transport system; advanced public transport system; indicator; smart mobility; fuzzy AHP

\section{Introduction}

Advanced technology has been utilized to improve transportation performance, such as to achieve smart mobility and gradually move to an autonomous era. The intelligent transport system (ITS) was first introduced in 1991 and has emerged as an important tool for promoting the efficiency of transportation. Some examples of ITS functions are traffic management centers, traffic signal control, travel information, commercial vehicle operations, advanced public transportation systems, electronic fare collection, and ridesharing and carsharing services [1].

In the past decade, ITS was applied to improve traffic and transport systems in Thailand. The Office of Transport and Traffic Policy and Planning (OTP) introduced the ITS master plan to formulate the direction of ITS development in Thailand from 2018 to 2027, in which the specific strategy "Assistive Public Transport" is indicated to improve public transport efficiency to encourage mobility behavior [2]. Recently, the cooperation between public and private sectors was promoted to upgrade the existing data system in order to provide effective valued-added information to the passengers especially relating to those on public transportation such as MOU among ViaBus and BMTA [3], and smart bus shelter by PLANB [4], as well as many public and private sectors have also emphasized the development of ITS service on smart mobility [3]. Yet, the 
integrated system for interoperability among each stakeholder is still the main issue in ITS development in Thailand resulting in the low percentage of public transportation usage in Bangkok Metropolitan Regions (BMR). Additionally, as the regulator of the ITS master plan, the OTP is lacking an assessment framework on ITS development. Although the master plan indicated the Key Performance Index (KPI) of project development assessment within each strategy, those indicators are not inclusive. The usage of public transportation in BMR is indicated for assessing the performance of the strategies of Advanced Public Transportation System (APTS) plan deployment, but the projects of APTS development can be evaluated in other dimensions such as reliability, mobility, safety and environment [5].

According to the ITS Master Plan [2], for APTS development, the projects can be categorized into five groups which consist of information systems, intelligent stations, standard formulation, common ticket systems and electronic and autonomous vehicles. However, during the short term of the master plan, the evaluation report of the ITS shortterm action plan [6] stated that only two out of ten projects of APTS development were implemented. In addition, the outcome of the implemented projects cannot represent the goals and objectives of the plan because there are no inclusive standard indicators to measure project development. As can be seen from Table 1, inappropriate measurement to indicate the output and outcome of the project implementation and budget investment may hinder the assessment of the impact and effectiveness of policy and plan deployment.

Table 1. Indicators of ITS master plan in BMR [2].

\begin{tabular}{|c|c|c|c|c|c|c|c|}
\hline \multirow{2}{*}{ Purpose } & \multirow{2}{*}{\multicolumn{2}{|c|}{ Strategy }} & \multirow{2}{*}{ Goals } & \multirow{2}{*}{ Indicators } & \multicolumn{3}{|c|}{ Target } \\
\hline & & & & & 3 Years & 5 Years & 10 Years \\
\hline \multirow{2}{*}{$\begin{array}{l}\text { ITS for } \\
\text { Green } \\
\text { Mobility }\end{array}$} & \multirow{2}{*}{$\begin{array}{c}\text { Automatic } \\
\text { Traffic } \\
\text { Management }\end{array}$} & $\begin{array}{l}\text { Assistive Public } \\
\text { Transport }\end{array}$ & $\begin{array}{c}\text { Promotion of } \\
\text { Public } \\
\text { Transport }\end{array}$ & $\begin{array}{l}\text { The proportion of public } \\
\text { transport users }\end{array}$ & $42 \%$ & $45 \%$ & $53 \%$ \\
\hline & & $\begin{array}{l}\text { Interactive } \\
\text { Demand } \\
\text { Management }\end{array}$ & $\begin{array}{l}\text { Mobility } \\
\text { Improvement }\end{array}$ & $\begin{array}{c}\text { Average speed on city streets network } \\
\text { during rush hour }\end{array}$ & $28 \%$ & $28 \%$ & $28 \%$ \\
\hline $\begin{array}{c}\text { ITS } \\
\text { Assistive } \\
\text { Solution }\end{array}$ & \multicolumn{2}{|c|}{ Intensive Transport Safety } & Safety Increase & $\begin{array}{l}\text { Number of road accident } \\
\quad \text { (per 100,000 times) }\end{array}$ & 0.28 & 0.24 & 0.13 \\
\hline \multirow{4}{*}{$\begin{array}{c}\text { ITS } \\
\text { Integrated } \\
\text { Center }\end{array}$} & \multirow{4}{*}{\multicolumn{2}{|c|}{ Integrative Mobility Center }} & \multirow{4}{*}{$\begin{array}{c}\text { Establishment } \\
\text { of an } \\
\text { Information } \\
\text { Integration } \\
\text { Center }\end{array}$} & $\begin{array}{l}\text { ITS integrated center authorities were } \\
\text { set up in BMR }\end{array}$ & - & Set up & Set up \\
\hline & & & & $\begin{array}{c}\text { Percentage of units that link data to } \\
\text { the center }\end{array}$ & - & $60 \%$ & $100 \%$ \\
\hline & & & & $\begin{array}{l}\text { Percentage of signal junction controlled } \\
\text { and commanded by the center }\end{array}$ & - & - & $100 \%$ \\
\hline & & & & $\begin{array}{l}\text { Percentage of traffic enforcement } \\
\text { camera connected to the center }\end{array}$ & - & - & $100 \%$ \\
\hline
\end{tabular}

According to the ITS evaluation literature, ITS application can provide different benefits from different perspectives and the multiple objectives of system development lead to the complexity of the measurement procedure [7]. The previous studies have applied many methods to access the benefits or expected outcomes of ITS [8]. To develop the evaluation platform, the indicators were elaborated to measure the project implementation or the application functions of ITS development. Much of the literature introduced MDCA through various methods such as AHP, FAHP, Group AHP and TOPSIS to investigate appropriate indicators and evaluation procedures relating to public transportation, Intelligent Transportation Systems and smart mobility [9-11]. In addition, the trend of ITS indicators has become multidimensional. FAHP method is introduced to mitigate uncertain human preference and express subjective assessment because the method applies to linguistic terms to represent the scaling. It was found to be flexible enough to deal with the inherent conditions of uncertainty [12-14], but they worked on public transportation or specific ITS applications. 
Therefore, this study proposes the development of significant indicators to propose an assessment framework of ITS for public transportation in BMR to support the systematic plan procedure to effectively emphasize the evaluation process and plan deployment. The proposed indicators were designated from the collection of indicators and dimensions related to ITS, public transportation, smart mobility, and sustainable transportation (see Section 2). The expected outcomes of APTS projects from the master plan are reviewed to scope the indicators. Then, the fuzzy analytic hierarchy process (fuzzy AHP) was applied to analyze possible significant criteria to determine indicators of ITS on public transportation in BMR (see Section 3). The result and discussion of the respondents are explained in Section 4.

\section{Literature Review}

\subsection{ITS and APTS Assessment Framework Subsection}

As ITS projects have become more comprehensive systems, evaluation of the implementation should be performed. There are some theories and studies on ITS measurement for both general ITS projects and a particularly advanced public transport system. The measurement criteria are mostly based on socioeconomic and environmental perspectives [15]. The evaluation method of ITS is highlighted as being more inclusive than conventional construction projects. The impact evaluation of ITS projects should be flexible for the integration development of ITS, particularly the qualitative benefits of the projects. The vital factor of the impact measurement assignment should be the agreement of related stakeholders [8]. In addition, to formulate the evaluation process, the United States Department of Transportation [16] stated that the conceptual process can be performed to measure the effect of the applicability of the system. The indicators of function features or pertinent information must be identified along with the objectives of the operation. The framework of the European Platform on Sustainable Urban Mobility Plans (SUMP) guides the development and implementation of sustainable mobility plans that the vision objectives should be defined to represent the future change. The significant indicators need to be identified by coordinating with relevant stakeholders [17].

Performance evaluation can be conducted by comparing the indicators before and after implementation. Some indicators related to APTS can be categorized based on qualitative and quantitative effectiveness, such as travel time, average speed, user perception, and level of service, including the reconsideration of advanced technology to support future systems and applications [18-22]. Additionally, the components of the ITS system can be referred to as the envisioned objectives of evaluation in terms of people, transport (vehicles), and space (infrastructure or environment) [23]. Otherwise, it can be categorized based on the type of application for ITS such as traffic management, diagnostic, environment, assistance and safety [24] or different data processing methods [25]. However, the tendency of sustainable development has been considered on projects. In terms of transportation, smart mobility should address accessibility, affordability, environmental friendliness, technology performance, and safety [12,26-34]. Moreover, performance can be monitored based on the quality of public transportation operators in terms of operability, user satisfaction, the efficiency of the services, safety, and reliability [35-39].

In brief, the performance indicators related to ITS and APTS can be identified into a hierarchy from the first level as a goal or main objective or index value, followed by the second level, which can be area, citation, or dimension of indicators, and the lowest level in individual variables that represent the performance or measurement of the above level. A compilation of the indicators used in this study is presented in Table 2. 
Table 2. Summary of criteria and indicators relating to APTS, Public transport and smart mobility.

\begin{tabular}{|c|c|c|}
\hline Authors & Indicator Categories & Ref. \\
\hline USDOT (1994) & APTS indicators and objectives & [16] \\
\hline Levine and Underwood (1996) & Outcomes of ITS development and goals & [40] \\
\hline Lomax, Vadali and Eisele (2000) & $\begin{array}{l}\text { Performance measurement and ITS goal and objectives within matrices of } \\
\text { economic, quality of life and environmental quality }\end{array}$ & [41] \\
\hline Yeh, Deng and Chang (2000) & To investigate bus company performance & [12] \\
\hline Hanaoko and Kunadhamraks (2008) & To evaluate logistic performance & [42] \\
\hline Dobranskyte-Niskota et al. (2009) & To assess sustainability of transport activities & [26] \\
\hline Othaman and Ku-Mahamud (2010) & To investigate the bus company performance & [35] \\
\hline Suwardo (2010) & $\begin{array}{l}\text { To figure out the performance of bus service system for public } \\
\text { transport improvement }\end{array}$ & [36] \\
\hline Shiau and Liu (2013) & $\begin{array}{l}\text { To find the goal of measuring transport sustainability at the country or } \\
\text { city level }\end{array}$ & [27] \\
\hline Shaheen and Finson (2013) & $\begin{array}{l}\text { Predicted Impacts for each ITS functions to elaborate the impact on } \\
\text { energy reduction }\end{array}$ & [1] \\
\hline Zou et al. (2014) & To evaluate urban public transportation in Kunming, China & [43] \\
\hline Ambrosino et al. (2015) & To assess ITS applications in public transport services & [37] \\
\hline AECOM (2015) & ITS KPIs in terms of deployment and benefit related & [44] \\
\hline Niglio and Comitale (2015) & Indicators of Sustainable Mobility Program & [28] \\
\hline Mitropoulos and Prevedouros (2016) & Indices of urban transportation vehicle-based assessment on sustainable theme & [39] \\
\hline Verseckiene, Palsaitis and Yatskiv (2017) & Indicators of sustainable theme to choose transportation service & [45] \\
\hline Bosch et al. (2017) & Indicators related to mobility for accessibility in smart city & [46] \\
\hline Wengler (2017) & Indicators of Mobility as a Service & [30] \\
\hline Krmac and Djordjevic (2017a) & $\begin{array}{l}\text { Proposed indicators for train control information systems for sustainable } \\
\text { railway evaluation }\end{array}$ & [47] \\
\hline Krmac and Djordjevic (2017b) & Proposed indicators for railway ITS evaluation & [48] \\
\hline Garau and Pavan (2017) & Indicators of accessibility under Smart Sustainable Cities & [49] \\
\hline Chen and Deng (2018) & Evaluation Criteria for sustainable transport solution assessment framework & [10] \\
\hline Lopez-Carreiro and Monzon (2018) & $\begin{array}{c}\text { Smartness indicators for Sustainability Transportation and Innovation } \\
\text { Transportation }\end{array}$ & [32] \\
\hline Creger, Espino and Sanchez (2018) & Recommended equity indicators in mobility framework & [33] \\
\hline Lee (2018) & $\begin{array}{l}\text { Sub-criteria to represent value of APTS, provider, and users to prioritize APTS } \\
\text { consideration for urban type }\end{array}$ & [38] \\
\hline Mlinaric, Djordjvevic and Krmac (2018) & Indicators to formulate evaluation framework for railway ITS & [50] \\
\hline Weng et al. (2108) & $\begin{array}{l}\text { Subindexes of Satisfaction Evaluation Index from passenger perspective to } \\
\text { bus service }\end{array}$ & [51] \\
\hline Longo, Zappatore and Navathe (2019) & $\begin{array}{l}\text { Indicators for delivered and for perceived to examine Quality of Service of } \\
\text { local public transport }\end{array}$ & [39] \\
\hline Cyril, Mulangi and George (2019) & $\begin{array}{l}\text { Performance optimization of public transport consideration by decision } \\
\text { Variable of user-oriented and operator oriented }\end{array}$ & [52] \\
\hline Buenk, Geobbelaar and Meyer (2019) & $\begin{array}{l}\text { Indicators to formulate framework for the sustainable assessment of } \\
\text { (Micro)transit systems }\end{array}$ & [53] \\
\hline $\begin{array}{l}\text { Zapolskyte, Burinskiene and } \\
\text { Trepanier (2020) }\end{array}$ & Indicators of measurement of smartness level of urban mobility & [34] \\
\hline Antolin et al. (2020) & $\begin{array}{l}\text { Sustainable index and smartness index to develop evaluation framework for } \\
\text { smartness and sustainability in cities }\end{array}$ & [7] \\
\hline
\end{tabular}


Table 2. Cont.

\begin{tabular}{|c|c|c|}
\hline Authors & Indicator Categories & Ref. \\
\hline Chao. Gallego and Lopez-Chao (2020) & $\begin{array}{l}\text { Indicators related to mobility and transportation in category under } \\
\text { environmental aspects, Mobility and Transport for sustainable urban design }\end{array}$ & [54] \\
\hline Chan et al. (2020) & $\begin{array}{l}\text { Questions to examine the response for } 6 \text { dimensions of Sustainability of } \\
\text { Public Transportation }\end{array}$ & [55] \\
\hline Yang, Dam and Zhang (2020) & $\begin{array}{c}\text { Indicators of sustainable and integrated transport infrastructure and urban } \\
\text { spaces design }\end{array}$ & [23] \\
\hline
\end{tabular}

\subsection{AHP, and Fuzzy AHP of Transportation, ITS, and Public Transportation}

Multi-criteria decision analysis (MDCA) is a method for solving the decision-making process by providing a compromise solution from various possible alternatives, including social conflicts and different stakeholder satisfaction [56]. The application of MDCA includes the techniques of mathematics, management, informatics, psychology, social, and economics to solve the decision of tactical and operational strategies [57]. The AHP, which was developed by Saaty [58], is a tool for solving multi-decisions based on perceptions, feelings, judgments, and memories in various dimensions to scale the hierarchy. The weighting is calculated by paired comparison with respect to dominance, which is represented by the number regarding the level of significance against each other. AHP has been widely used to support decision-making in various sectors and developed with other methods such as linear programming, data envelopment, fuzzy sets, house of quality, and SWOT analysis $[9,11]$. The advantage of AHP is the property to evaluate the preference scale by numerical, verbal or graphical, but the absolute preference cannot be represented with ratio scales. Thus, the expended AHP is developed to solve the uncertainty of human judgment. One of the widely used methods is to apply a fuzzy set to define the ratio scale of verbal discretion [11].

Some studies examined that the theory of fuzzy sets can be applied to solve uncertain determination such as very, nearly, or rarely in particularly the different of people interpretation [12-14]. For example, Yeh et al. [12] and Othman and Ku-Muhamud [35] applied a fuzzy singleton matrix to evaluate the bus companies' performance. Kabir and Hasin [14] applied the concept of fuzzy AHP according to Chang (1996) [59] with triangle fuzzy to define the means of FAHP for pairwise comparison, then calculate the weights by using synthetic extent values. Lee et al. [60] integrated FAHP with patent analysis tools to identify the selection of electric vehicle battery technology.

Considering the literature in Table 2, the criteria consideration is important to the hierarchy structure process to represent the objective or goal of the hierarchy. In terms of transportation, the evaluation of transport performance focuses on effectiveness in many dimensions, such as utility, mobility, operability, and accessibility. The ranking results are proposed to consider plan and policy decision making, which also contains many processes, particularly priority determination in planning and assessment, to improve the performance of transportation system development. Thus, a hierarchy analysis is preferred [61].

In ITS, public transportation and smart mobility related, AHP has been utilized to both scale indicator weighting and choose appropriate applications to implement $[35,39,48,62,63]$. Other extended AHP, such as fuzzy AHP, group AHP, and fuzzy and TOPSIS, were developed to solve inherent fuzziness of preference. These methods were applied to weight important performance index or indicators for general public transportation, ITS and smart mobility theme $[49,51,64-67]$ as well as to assess performance for supporting decision making and deciding best alternatives [10,12,32,36,43,44,46,68-71]. The difficulty of intelligent transportation system performance measurement is to assess the different objectives of the development, which can mitigate the complexity of impact assessment by weighting each criterion with a priority value [15]. Then, the fuzzy AHP method can be applied in ITS impact evaluation because it can solve the conflicts of multiple agencies 
related to the complex decision-making process. Some studies have applied AHP with a fuzzy set to mitigate some disadvantages of AHP in cases of an uncertain decision to a number of linguistic variables $[23,36,59]$.

In brief, fuzzy AHP has been utilized to prioritize the significance of the multi-criteria dimension of decision-making with a certain justification by applying linguistic representation in many areas. The advantage of the method is to be able to provide a flexible environment in dealing with the fuzziness of perception in the decision-making process. The fuzzy set allows making a decision in terms of interval judgment while primary AHP defines the absolute ratio scale to represent the assessment [12-14,65]. However, in some studies that applied fuzzy AHP, the user acceptance dimension on ITS functions to facilitate the public transportation service was not included, whereas, in other studies, fuzzy AHP was applied to ITS on specific public transportation modes or general urban transportation. Therefore, this study proposes a set of indicators of APTS extracted from applications and projects on buses, railways, and waterways that contribute to smart mobility perspectives. Furthermore, the proposed indicators were categorized and distributed by experts, who indicated that the important weights were from public, private, and institutional sectors to represent people, infrastructure, and vehicles through APTS projects in BMR.

\section{Research Methodology and Materials}

In order to determine the significant indicators and assessment framework of ITS on public transportation in BMR, the dimension and indicators are considered to formulate a fuzzy AHP structure and calculate the weight of each indicator. Furthermore, the opinion questions are attached to collect comments and recommendations of APTS development and assessment framework of APTS development in BMR.

A questionnaire is designated to collect pairwise comparisons of fuzzy AHP from 25 ITS experts by considering the experts of ITS planning and project development from public agencies, private agencies, and academic agencies. The respondents are required to have experience in ITS planning and project development of more than 5 years. The questionnaire is attached with the objective of the study, fuzzy AHP scaling, and definition of dimension and indicators, and then distributed to the experts by email. Furthermore, an online meeting was arranged to collect the survey result with the expertise from the executive level of the public sector while others provide their feedback by email.

\subsection{Dimension and Indicator Determination}

\subsubsection{Dimension Determination}

The available literature related to benefits, expected outcomes, and performance indicators of public transportation, APTS, and smart mobility was collected from online sources. Then, the abstract was reviewed to select related articles, the articles were read, and the indicators related to the study topic were summarized.

Although the concepts of smart and sustainable transportation have been used interchangeably, they are not equivalent [7]. In this study, the related indicators from both terms were identified. First, a search was conducted on https:/ / scholar.google.com with a target range of 1995 to 2021 (as of 12 May 2021) by two main keywords, which were "indicator" + "advanced public transportation system" and "smart mobility" + "indicator" + "public transportation." The search results presented 118 and 848 articles, respectively. With the manual search related to the evaluation framework of ITS and APTS of 23 articles, 989 articles were included in the preliminary search. Next, the abstracts of the articles were reviewed focusing on objectives and keywords to select related articles, resulting in 81 articles; finally, the articles were fully read to identify the mentioned indicators. Therefore, the total number of articles was 35 . The criteria for article selection are presented in Table 3. 
Table 3. Criteria of article consideration.

\begin{tabular}{|c|c|}
\hline Criteria Category & Conditions \\
\hline Inclusion Criteria & $\begin{array}{ll}- & \text { Research published in academic journals } \\
\text { - } & \text { Full access to full-text } \\
\text { - } & \text { Research published since } 1995 \\
\text { - } & \text { Research covering indicators of public } \\
& \text { transportation, APTS, smart mobility }\end{array}$ \\
\hline Exclusion Criteria & $\begin{array}{ll}\text { - } & \text { Non-English } \\
\text { - } & \text { Research does not include inner-urban } \\
& \text { public transportation such as airports } \\
\text { - } & \text { Research does not include the indicators }\end{array}$ \\
\hline
\end{tabular}

Then, the keywords of the articles selected by the criteria from Table 3 were collected and examined using https://voyant-tools.org/ (accessed on 28 May 2021), which is a free online tool to determine the frequency of words by user input. The most frequent keywords are shown in Figure 1. These worlds were further grouped to identify the fuzzy AHP criteria.

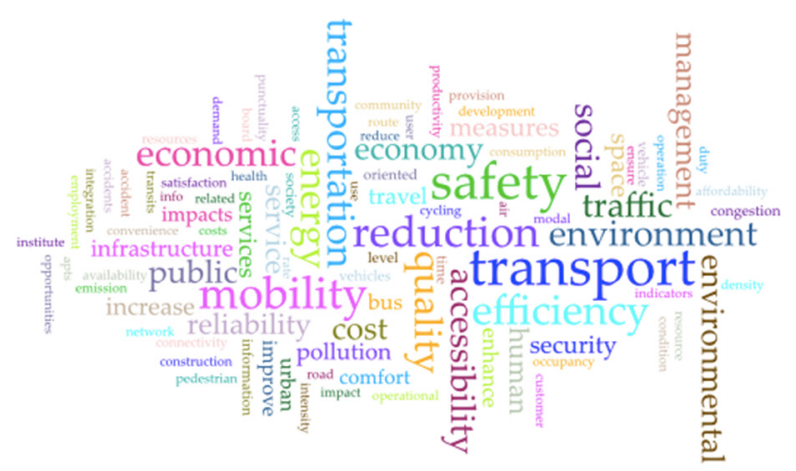

Figure 1. Frequency words from selected articles.

In accordance with the projects proposed in the ITS master plan [2], two main tactics under the strategy of Assistive Public Transport are "Encourage information development for trip planning with public transport" and "Use ITS for potential public transport services." The objectives of each project from information systems, intelligent stations, standard formulation, common ticket systems and electronic and autonomous vehicles, were elaborated to link with the frequent words from the literature articles to identify the appropriate criteria of indicators for BMR. There are six dimensions which consist of mobility, efficiency, reliability, accessibility, environment, and safety.

In this study, mobility refers to the outcome of APTS implementation to support passenger mobility $[22,46,55]$. Efficiency is considered the efficiency of a system that reflects a more advanced system, modal share improvement, and user satisfaction $[16,30,43]$, whereas reliability focuses on the continuity and consistency of the system $[16,30,43,44]$. Accessibility refers to physically accessible features and how the APTS supports passenger access to public transportation $[26,31,35,46]$. The environment is considered as the impact and benefit of system development in the environment [1,7,10,26,27,54]. Lastly, safety refers to how APTS can support safety management systems related to public transportation $[12,16,41,47,48]$.

\subsubsection{Indicator Determination}

The proposed indicators were considered under the criteria of dimension, namely mobility, efficiency, reliability, accessibility, environment, and safety. The full list of indicators was collected from Table 2 for reviewing and considering the APTS-related, which resulted in 189 indicators. The criteria for indicator contemplation are presented in Table 4. 
Table 4. Criteria of indicator contemplation.

\begin{tabular}{|c|c|}
\hline Criteria Category & Conditions \\
\hline Inclusion Criteria & $\begin{array}{ll}\text { - } & \text { Related to APTS } \\
\text { - } & \text { Represent the impact of APTS } \\
\text { - } & \text { Represent objectives of projects under } \\
\text { - Thailand ITS master plan } \\
\text { - } \\
\text { Possibility in collecting data for } \\
\text { measurement } \\
\text { Provide clear definition including how to } \\
\text { calculate the measurement }\end{array}$ \\
\hline Exclusion Criteria & $\begin{array}{ll}\text { - } & \text { No clear definition } \\
\text { - } & \text { Redundant meaning or } \\
\text { - } & \text { No availability to collect data for } \\
& \text { measurement in Thailand }\end{array}$ \\
\hline
\end{tabular}

The shortlist of indicators was then deliberated in accordance with the possible available services from projects under the ITS master plan and current ITS systems in BMR and finalized by removing the redundant and indirect indicators related to APTS. Finally, 21 prospective indicators were determined within the six dimensions to represent APTS development in BMR. The proposed hierarchical dimensions and indicators are shown in Figure 2.

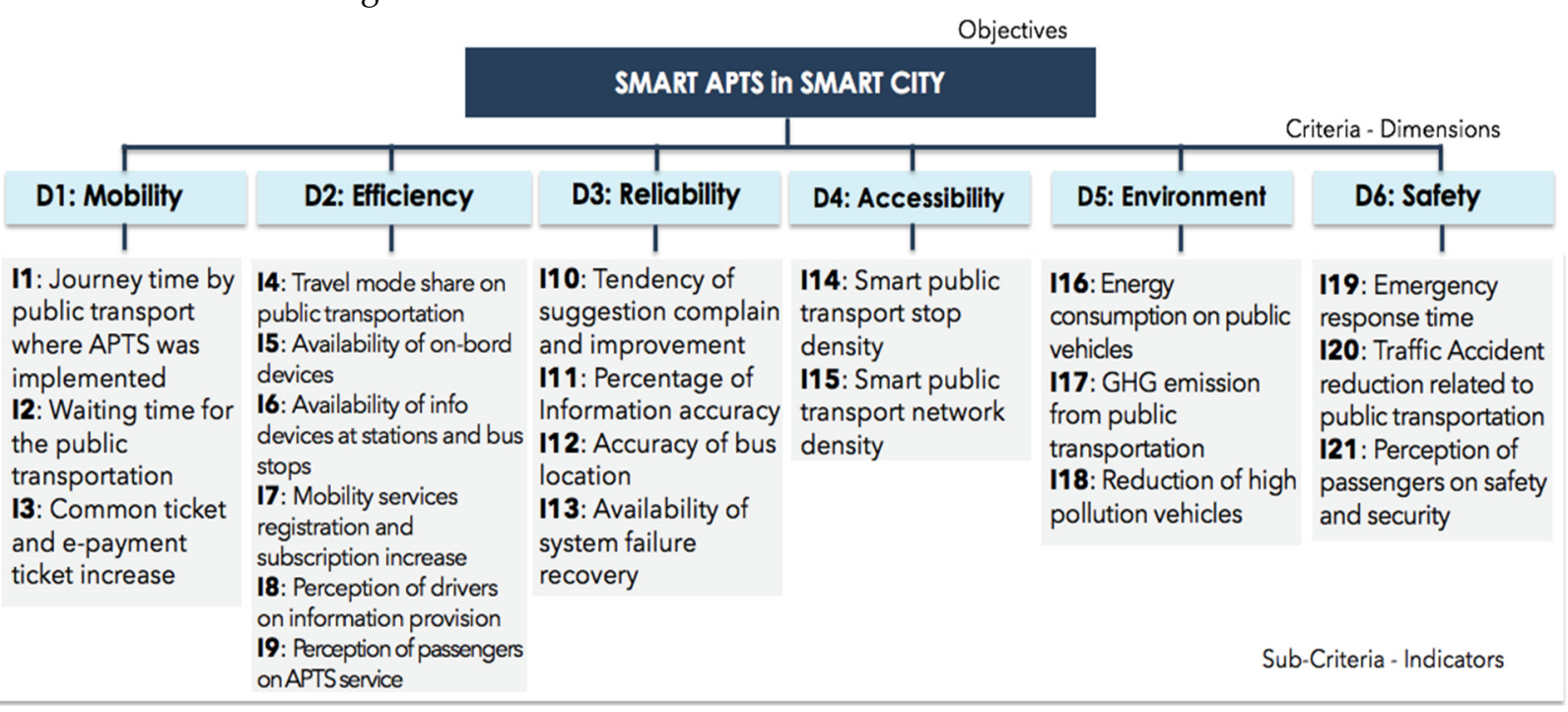

Figure 2. Hierarchal structure for ranking indicators on APTS in BMR.

\subsection{Dimension and Indicator Weighting Analysis by Fuzzy AHP}

In this study, the fuzzy APH procedure from [14] which applied Chang's [59] methodology complemented by [72] was adopted to examine the weighting of dimension and important ranking indicators. The weights were prioritized for the important dimensions and indicator ranking. The sequence of weighting dimensions and indicators is presented in Figure 3. 


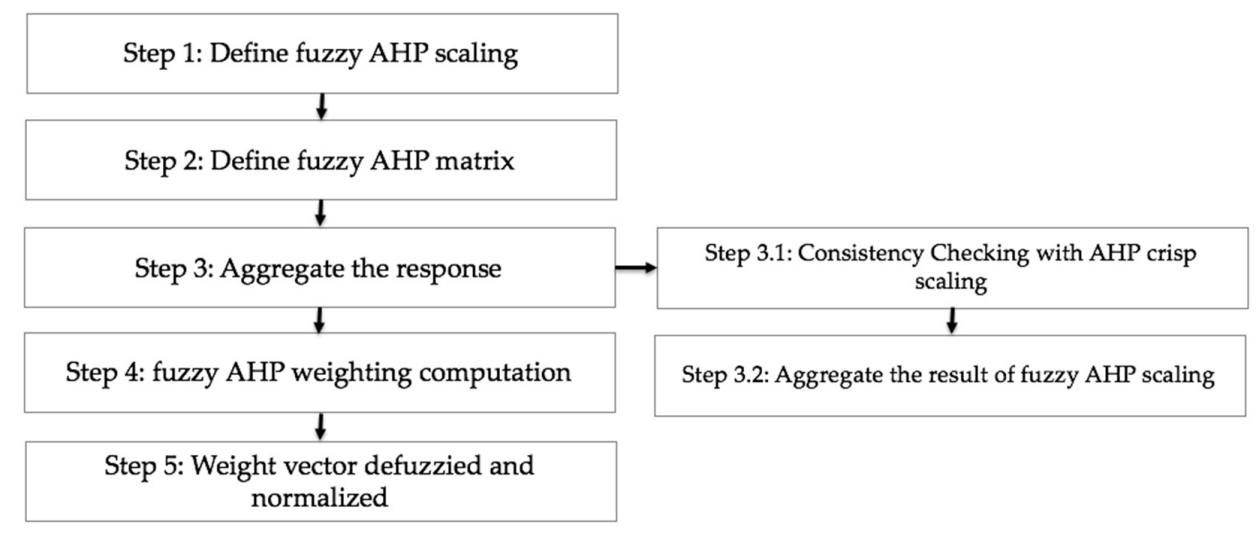

Figure 3. Fuzzy AHP computation concept.

Step 1 Fuzzy scaling: The linguistic variables are applied to represent the respondents rating importance, which is represented by Fuzzy Triangle Member (FTM) in Figure 4.

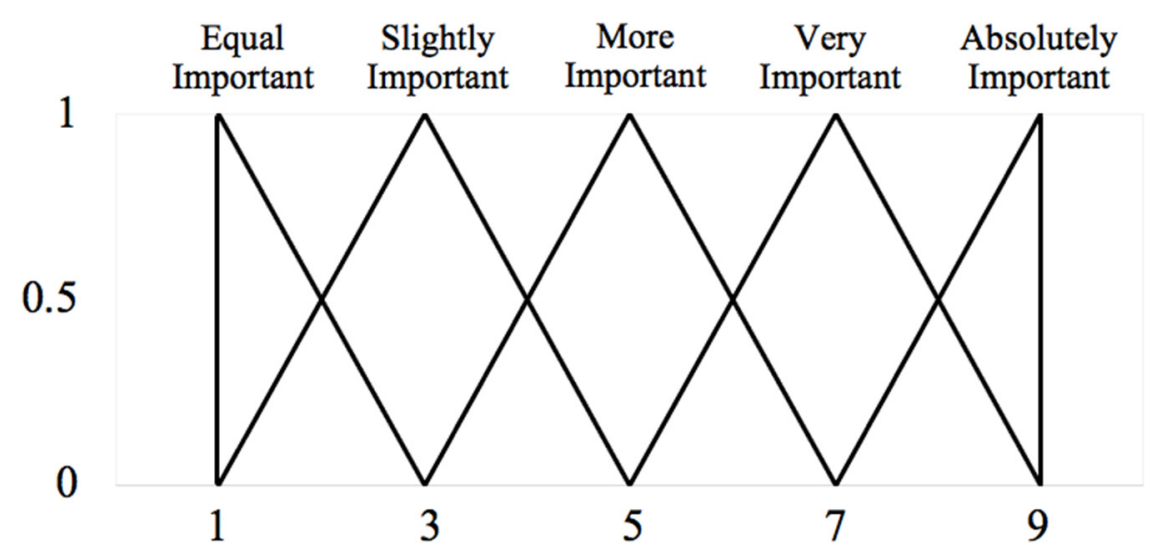

Figure 4. Fuzzy triangle member for linguistic variables of important weight [14].

Then, the intensity importance scaling is represented by the fuzzy triangle member (FTM) $\widetilde{m}_{i j}$ as shown in Equation (1) and Table 5.

$$
\widetilde{m}_{i j}=\{l, m, u\}
$$

where $l$ is lower, $\boldsymbol{u}$ is upper, and $m$ is median.

Table 5. Fuzzy AHP scale for APTS dimension and indicator weighting (adopted from [14]).

\begin{tabular}{lcccc}
\hline $\begin{array}{c}\text { Linguistic Scale of } \\
\text { Importance }\end{array}$ & $\begin{array}{c}\text { AHP Crisp } \\
\text { Scale }\end{array}$ & $\begin{array}{c}\text { Fuzzy } \\
\text { Scale }\end{array}$ & $\begin{array}{c}\text { Fuzzy Triangle } \\
\text { Member }\end{array}$ & $\begin{array}{c}\text { Defuzzied } \\
\text { Triangle Member }\end{array}$ \\
\hline EI.: Equal Importance & 1.333 & $\widetilde{1}$ & $(1,1,3)$ & $(1 / 3,1,1)$ \\
SI.: Slightly Importance & 3 & $\widetilde{3}$ & $(1,3,5)$ & $(1 / 5,1 / 3,1)$ \\
MI.: More Importance & 5 & $\widetilde{5}$ & $(3,5,7)$ & $(1 / 7,1 / 5,1 / 3)$ \\
VI.: Very Importance & 7 & $\widetilde{7}$ & $(5,7,9)$ & $(1 / 7,1 / 9,1 / 5)$ \\
AI.: Absolutely Importance & 8.667 & $\widetilde{9}$ & $(7,9,9)$ & $(1 / 9,1 / 9,1 / 7)$ \\
\hline * Transform FTM to numerical AHP crisp scale by $a_{i j}$
\end{tabular}

${ }^{*}$ Transform FTM to numerical AHP crisp scale by $a_{i j-c r i s p}=(l+4 m+u) / 6[72]$. 
Step 2 Establish fuzzy AHP matrix: The fuzzy AHP matrix $\left(\widetilde{M}_{i j}\right)$ is defined to represent the expert scaling to the questionnaire as the Equation (2):

$$
\widetilde{M}_{i j}=\left[\widetilde{m}_{i j}\right]_{i, j=1, \ldots, n}=\left[\begin{array}{cccc}
1 & \widetilde{m}_{12} & \cdots & \widetilde{m}_{1 n} \\
\frac{1}{\widetilde{m}_{12}} & 1 & \cdots & \widetilde{m}_{2 n} \\
\vdots & \vdots & \ddots & \vdots \\
\frac{1}{\widetilde{m}_{1 n}} & \frac{1}{\bar{m}_{2 n}} & \cdots & 1
\end{array}\right]
$$

Step 3 Aggregate the Scaling of the Interviewee: The geometric mean method is applied to aggregate the combined fuzzy AHP for each stakeholder group and for all groups, as defined in Equation (3) [73].

$$
\widetilde{r}_{i}=\left(\prod_{i=1}^{n}\left(\widetilde{m}_{i j}\right)\right)^{\frac{1}{n}}
$$

where $\widetilde{r}_{i}$ is the geometric mean of fuzzy numbers.

However, before calculating the fuzzy AHP weighting, the consistency ratio (CR) is required to compute the consistency of the constructed matrix verification. Thus, the AHP crisp scale from Table 5 is replaced to calculate the consistency index $(C I)$ and $C R$, as shown in Equations (3) and (4), respectively [58].

$$
\begin{gathered}
C R=\frac{C I}{R I} \\
C I=\frac{\left(\lambda_{\max }-n\right)}{(n-1)}
\end{gathered}
$$

where $R I$ is the random index [58].

Then, the crisp scales are aggregated by the geometric mean. The constructed matrix is consistent if $C R \leq 0.05$ for a matrix $3 \times 3$, or $C R \leq 0.08$ for a matrix $4 \times 4$, and $C R \leq 0.1$ for a matrix larger than $5 \times 5$ [58]. The $C R$ is calculated to check the consistency of responses which resulted within the condition.

Therefore, the matrices of fuzzy AHP scaling by ITS experts from the questionnaires are aggregated to enumerate the comparison weighting in the next step by geometric mean.

Step 4 Fuzzy AHP weighting computation: First, the fuzzy synthetic extent $\left(S_{i}\right)$ of the dimension and indicator set is determined by Equation (6).

$$
S_{i}=\sum_{j=1}^{m} M_{g_{i}}^{j} \otimes\left[\sum_{i=1}^{n} \sum_{j=1}^{m} M_{g_{i}}^{j}\right]^{-1}
$$

where $\sum_{j=1}^{m} M_{g_{i}}^{j}=\left(\sum_{i=1}^{m} a_{i}, \sum_{i=1}^{m} b_{i}, \sum_{i=1}^{m} c_{i}\right), \sum_{i=1}^{n} \sum_{j=1}^{m} M_{g_{i}}^{j}=\left(\sum_{i=1}^{n} a_{i}, \sum_{i=1}^{n} b_{i}, \sum_{i=1}^{n} c_{i}\right)$, and $\left[\sum_{i=1}^{n} \sum_{j=1}^{m} M_{g_{i}}^{j}\right]^{-1}=\left(\frac{1}{\sum_{i=1}^{n} c_{i}}, \frac{1}{\sum_{i=1}^{n} b_{i}}, \frac{1}{\sum_{i=1}^{n} a_{i}}\right)$.

Then, the degree of possibility of $V\left(M_{2} \geq M_{1}\right)$ is considered in Equation (7) as:

$$
V\left(M_{2} \geq M_{1}\right)=\sup \left[\min \left(\mu_{M_{1}}(x), \mu_{M_{2}}(x)\right)\right]
$$

where $V\left(M_{2} \geq M_{1}\right)=\operatorname{hgt}\left(\widetilde{M}_{1} \cap \widetilde{M}_{2}(d)\right)=\left\{\begin{array}{r}1, \text { if } b_{2} \geq b_{1} \\ 0, \text { if } a_{1} \geq c_{2} \\ \frac{a_{1}-c_{2}}{\left(b_{2}-c_{2}\right)-\left(b_{1}-a_{1}\right)}, \text { otherwise }\end{array}\right.$

Then $V\left(M \geq M_{1}, M_{2}, \ldots, M_{k}\right)=V\left[\left(M \geq M_{1}\right)\right.$ and $\left(M \geq M_{2}\right)$ and $\left.\ldots\left(M \geq M_{k}\right)\right]=$ $\min V\left(M \geq M_{i}\right),(i=1,2,3, \ldots, k)$. 
After the minimum degree of possibility is acquired as $d^{\prime}\left(A_{i}\right)=\min V\left(S_{i} \geq S_{k}\right)$ for $k=1,2,3, \ldots, n ; k \neq i$, the weight vector $\left(W^{\prime}\right)$ of each dimension is obtained by Equation (8).

$$
V\left(M_{2} \geq M_{1}\right)=\sup \left[\min \left(\mu_{M_{1}}(x), \mu_{M_{2}}(x)\right)\right]
$$

where $A_{i}=(i=1,2,3, \ldots, n)$ are $n$ elements.

Step 5 Weight Vector Defuzzied and Normalized: each vector is normalized to decide the priority weight of each dimension over another dimension by Equation (9).

$$
V\left(M_{2} \geq M_{1}\right)=\sup \left[\min \left(\mu_{M_{1}}(x), \mu_{M_{2}}(x)\right)\right]
$$

\subsection{Opinion Survey Analysis}

In Part 2 of the questionnaire, five opinion questions are attached to collect the experts' perspectives of APTS development and the assessment framework of APTS development in BMR. The objectives of these questions are to reflect current issues, challenges and recommendations of APTS development. The opinions from all experts are examined and interpreted to contemplate the consensus of assessment framework consideration by descriptive analysis. The questions in Part 2 are listed as follows:

1. What is the most important for APTS development in Thailand?

2. What is the most challenge of APTS development in Thailand?

3. How can the responsible agencies improve the planning process of APTS in Thailand?

4. What is the biggest challenge of system evaluation in Thailand?

5. How can the responsible agencies improve the evaluation process?

\section{Result of Questionnaires and Discussion}

The results from the questionnaires are analyzed to examine the scaling of indicator weighting and the opinions of respondents. The discussions of each part are attached to address the important dimension and indicators, and perspectives of APTS assessment framework development in BMR.

\subsection{Fuzzy AHP Weighting of APTS}

The fuzzy AHP weighting step was repeated to acquire each indicator weight within each dimension. Regarding the hierarchy of the proposed indicators, the total weight of each indicator in a level with respect to a dimension was obtained by multiplying by the weight of that dimension [56]. Then, the priority of each indicator compared to that of others was ranked to represent the significant measurement of APTS development in BMR from the experts' perspective. The final weights of the proposed indicators for APTS development in the BMR are presented in Table 6 and Figure 5.

\begin{tabular}{|c|c|c|c|c|c|c|}
\hline Dimension & $W_{D i}$ & Indicators & $W_{I i}$ & Total Weight & Percentage & Rank \\
\hline \multirow{3}{*}{ D1: Mobility } & \multirow{3}{*}{0.177} & $\begin{array}{l}\text { I1: Journey time by public transport where APTS was } \\
\text { implemented }\end{array}$ & 0.429 & 0.0758 & $7.580 \%$ & 6 \\
\hline & & I2: Waiting time for the public transportation & 0.489 & 0.0863 & $8.628 \%$ & 3 \\
\hline & & I3: Common ticket and e-payment ticket increase & 0.082 & 0.0144 & $1.442 \%$ & 18 \\
\hline \multirow{6}{*}{ D2: Efficiency } & \multirow{6}{*}{0.164} & I4: Travel mode share on public transportation & 0.278 & 0.0454 & $4.544 \%$ & 10 \\
\hline & & I5: Availability of on-board devices & 0.200 & 0.0327 & $3.271 \%$ & 11 \\
\hline & & I6: Availability of info devices at stations and bus stops & 0.170 & 0.0278 & $2.783 \%$ & 13 \\
\hline & & $\begin{array}{l}\text { I7: Mobility services registration and subscription } \\
\text { increase }\end{array}$ & 0.182 & 0.0297 & $2.969 \%$ & 12 \\
\hline & & I8: Perception of drivers on information provision & 0.059 & 0.0097 & $0.970 \%$ & 21 \\
\hline & & I9: Perception of passengers on APTS service & 0.111 & 0.0182 & $1.817 \%$ & 17 \\
\hline
\end{tabular}

Table 6. Result of weighting allocation for APTS development in BMR. 
Table 6. Cont.

\begin{tabular}{|c|c|c|c|c|c|c|}
\hline Dimension & $W_{D i}$ & Indicators & $W_{I i}$ & Total Weight & Percentage & Rank \\
\hline \multirow{4}{*}{ D3: Reliability } & \multirow{4}{*}{0.184} & I10: Tendency of suggestion complain and improvement & 0.327 & 0.0602 & $6.015 \%$ & 19 \\
\hline & & I11: Percentage of Information accuracy & 0.317 & 0.0583 & $5.834 \%$ & 7 \\
\hline & & I12: Accuracy of bus location & 0.279 & 0.0514 & $5.143 \%$ & 8 \\
\hline & & I13: Availability of system failure recovery & 0.464 & 0.0842 & $8.419 \%$ & 9 \\
\hline \multirow{2}{*}{ D4: Accessibility } & \multirow{2}{*}{0.182} & I14: Smart public transport stop density & 0.536 & 0.0974 & $9.744 \%$ & 4 \\
\hline & & I15: Smart public transport network density & 0.289 & 0.0191 & $1.908 \%$ & 2 \\
\hline \multirow{3}{*}{$\begin{array}{l}\text { D5: } \\
\text { Environment }\end{array}$} & \multirow{3}{*}{0.066} & I16: Energy consumption on public vehicles & 0.295 & 0.0195 & $1.948 \%$ & 16 \\
\hline & & $\begin{array}{c}\text { I17: Green House Gas (GHG) emission from public } \\
\text { transportation }\end{array}$ & 0.416 & 0.0274 & $2.744 \%$ & 15 \\
\hline & & I18: Reduction of high pollution vehicles & 0.340 & 0.0776 & $7.759 \%$ & 14 \\
\hline \multirow{3}{*}{ D6: Safety } & \multirow{3}{*}{0.228} & I19: Emergency response time & 0.607 & 0.1385 & $13.845 \%$ & 5 \\
\hline & & $\begin{array}{l}\text { I20: Traffic Accident reduction related to } \\
\text { public transportation }\end{array}$ & 0.053 & 0.0121 & $1.211 \%$ & 1 \\
\hline & & I21: Perception of passengers on safety and security & 0.429 & 0.0758 & $7.580 \%$ & 20 \\
\hline
\end{tabular}

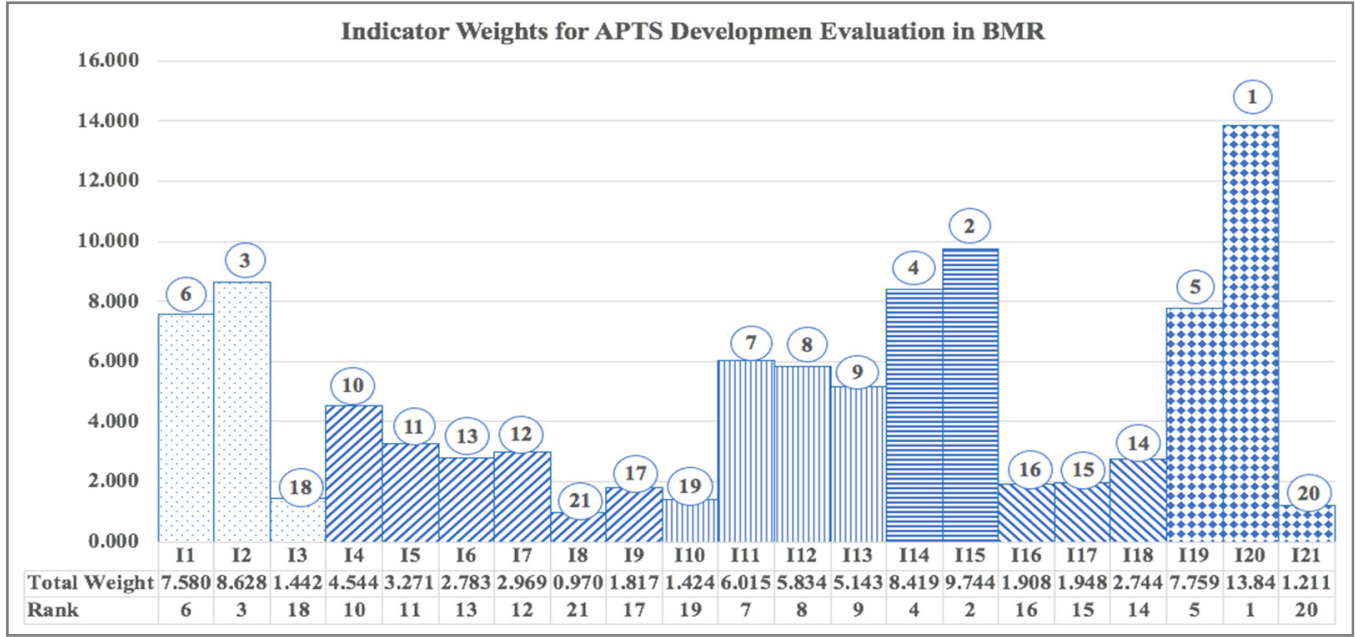

Figure 5. Total weight of indicators for APTS development assessment in BMR.

According to the weighting result by fuzzy AHP from Table 6 and Figure 5, in the expert perspective from the public sector, private sector and institutional sector, it is important to focus on the related safety of APTS. The most significant outcome of the applications of APTS should support the reduction of the traffic accident rate (I21) followed by smart public transport stop density (I15).

Although the smart public transport stop density (I14) acquires the rank of fourth place followed by the waiting time or public transportation (I2) within the mobility dimension. It can be inferred that the accessibility is highlighted to focus for project objective considering in BMR. The following significant indicators are also within the safety and mobility theme, the emergency response time (I19), journey time by public transportation where APTS was implemented (I1) respectively. Therefore, to achieve the goal of smart mobility by public transport, the accountable agencies should consider the development of applications and projects which serve safe transportation while promoting the accessibility and mobility of public transportation to promote public transportation usage.

Furthermore, the reliability dimension is addressed the following considerable indicator by the percentage of information accuracy (I11), accuracy of bus location (I12), and availability of system failure recovery (I13). The plan makers, therefore, meditate the outcome of reliable applications and services as it can have an impact on the confidence of public transportation users. The following weights within the efficiency dimension can 
indicate the importance of travel mode share on public transportation (I4), Availability of on-board devices (I5), mobility services registration and subscription increase (I7), and availability of info devices at stations and bus stops (I6). These impact measurements of the system can equip the quality of the services. Nonetheless, the environment is the least influence on important assessment according to the expert perspectives. The result presents the aim of the reduction of high pollution vehicles (I18) obtained the highest scaling followed by Green House Gas (GHG) emission from public transportation (I17) and energy consumption on public vehicles (I16).

With the fuzzy AHP weighting by the experts, some indicators from efficiency (perception of passengers on APTS service (I9)), perception of drivers on the information provided (I8)), mobility (common ticket and e-payment ticket increase (I3)), reliability (trend of suggestion, complain and improvement (I10)), and safety (perception of a passenger on safety and security (I21)), are ranked as the least important indicators. Although the proposed indicators related to user perspective including the driver are assigned the least weight, the majority of project objectives of APTS development in BMR should aim to contribute the user perspectives in evaluating the outcome of services to reflect the benefit of the projects to users $[16,18-21,41]$.

As can be seen from a result of indicator weighting, the impact of safety, accessibility and mobility are emphasized to reflect the challenge of the relative APTS development in BMR from the experts' aspect. Most of the first 10 most weight indicators designate the impact and outcome indicators of the systems, in addition to the output measurement of development. For instance, the proper result of the reduction of traffic accidents (I20) or waiting time (I2) can be acquired if the system can provide accurate and suitable information publishing to users for decision making. It does not require only the number of advanced sensors or equipment installation, but the appropriate cooperated system establishment is also thorough essential. Moreover, the result of the ranking can indicate that the indicators, which measure the output of the project such as the availability of on-board devices (I5), number of services registration and subscription increase (I7), and the number of availabilities of information devices at stations (I6), are examined as less important factors. Yet the ratio of APTS implementation of public transportation routing and stations (I14 and I15) is ordered at the highest rank, the aim is to improve the smart mobility on accessibility to public transportation.

Furthermore, the weighing on dimensions and indicators are varied among each sector. Although respondents from public and academic sectors ranked safety as the most important, the following dimension rankings are different. The experts from public sectors focus on reliability, accessibility and mobility while the specialists from institutes provided the ranking as accessibility, reliability and mobility. However, the least three dimensions are the same ranking from both sectors, which list mobility, efficiency and environment, respectively. Nonetheless, the private sectors weigh the rankings differently. The most important dimension is reliability followed by mobility, accessibility, and safety.

All sectors ranked efficiency and environment as the least two important dimensions. It can be seen that the different backgrounds of the respondents can cause the different focus on APTS development. The respondents from the public and academic sectors focus more on safety. They might consider that the outcome of the system development should support safe transportation. On the other hand, the respondents from the private sector probably implied that the reliability of the APTS can encourage people to use more public transportation. It can also indicate that the current APTS applications have not provided accurate information to users.

For indicator ranking, all sectors scaled the reduction of traffic accident rate and smart public transportation density at the most important followed by waiting time, smart public transport stop density, and emergency response time. It can be implied that the expected outcome of APTS development should consider emerging mobility and accessibility as well. It can be seen that the weighting of environment and user perspectives from each sector obtained the least important ranking, which is relevant to the overall weighting. 
Furthermore, there are three main differences between the indicators from the ITS Master Plan and the proposed indicators from this study. Firstly, the portion of public transportation usage is not ranked as the most important while the master plan focuses only on this indicator to represent the goal of the project development within the specific strategy. Another different point of view is the dimension of project assessment. With the design of indicators and dimensions for project development, the scope of indicators is more inclusive. The reliability, accessibility and environment dimensions are not included in the master plan. For example, the strategy of the data integration in the master plan aims to establish the integration center, the indicators of the percentage of equipment installation are set to refer to the accomplishment with regards to the master plan. It might not certify the achievement of the project without the reliability measurement. Lastly, the indicators from the master plan focus on more output of the development. For instance, the perspective of the user is not indicated to consider. Even the proposed indicators related to user perspective can acquire a least important, it can cause an issue on user acceptance of the services resulting in system deterioration.

\subsection{Experts' Perspective Analysis}

With the responses from opinion questions in Part 2 of the questionnaire, the answers are classified into the categories of similarity point of view from the experts in each question. Each category is expressed by a count of expert opinions, and some experts provide opinions in more than one category for one question. From a total of 25 experts, there are four no responses in Part 2 of the questionnaire. Therefore, the response is $84 \%$ of the total respondents. Table 7 presents the summary of the most frequent perspectives from the respondents.

Table 7. The most frequent responses from experts toward the opinion questions.

\begin{tabular}{lc}
\hline \multicolumn{1}{c}{ Categories } & No. of Response \\
\hline \multicolumn{1}{c}{ Question 1: What is the most important for APTS development in Thailand? } \\
\hline - Law and related regulation & 9 \\
\hline - Policy and action plan & 7 \\
\hline - Technology and adaptation & 5 \\
\hline - Integrated and intermediated organization and cooperation & 4 \\
among stakeholders & \\
\hline - Quality of reliability and efficiency of system and service & 9 \\
\hline \multicolumn{1}{c}{ Question 2: What is the most challenge of APTS development in Thailand? } \\
\hline - Reliability and efficiency of system and services & 6 \\
\hline - Integration among systems and services & 5 \\
\hline - Definite and consecutive policy & 4 \\
\hline - Technology and adaptation & \\
\hline - Law and restriction & \\
\hline - Capacity building and knowledge & \\
\hline Question 3: How can the responsible agencies improve for planning process of APTS in Thailand? \\
\hline - Integrated and cooperative planning procedure & 9 \\
\hline - Law and restriction adjustment & \\
\hline - System standard and architect formulating & \\
\hline - Definite goals, objectives and action plans & \\
\hline - Evaluation or assessment framework formulating & \\
\hline
\end{tabular}


Table 7. Cont.

\begin{tabular}{lc}
\hline \multicolumn{1}{c}{ Categories } & \multicolumn{1}{c}{ No. of Response } \\
\hline \multicolumn{2}{c}{ Question 4: what is the most challenge of system evaluation in Thailand } \\
\hline - Evaluation platform formulating & 7 \\
\hline - Integration and cooperation among stakeholders & 4 \\
\hline - Information presentation of evaluation report & 3 \\
\hline - Outcome and impact of project assessment & 7 \\
\hline - Consonant communication of goals and objectives among stakeholders & 6 \\
\hline \multicolumn{2}{c}{ Question 5: how can the responsible agencies improve the evaluation process? } \\
\hline - Effective evaluation system including reliable information \\
$\begin{array}{l}\text { of measurement } \\
\text { - Evaluation platform and procedure formulation }\end{array}$ \\
\hline $\begin{array}{l}\text { - Specific organization for evaluation with advocated regulation } \\
\text { - Integration system including open data and data integration with both } \\
\text { public and private }\end{array}$
\end{tabular}

According to Table 7, the respondent perspectives towards the opinion questions about APTS development can be extracted into two main sessions (1) APTS application development, and (2) assessment procedure forming. Firstly, Question 1-Question 3 are related to key factors and challenges of APTS planning and development. The responses can be concluded that the impediment of policy and regulation is the adherent crucial success factor and challenge to support the development and assessment prosperously. It is also noteworthy that integration and cooperation among related stakeholders play an important role as a fundamental feature of system development to serve smart mobility, which can be compromised by a concurrence of standard and architecture principles. The planning procedure is needed to state the definite goals, objectives and action plans to draw the direction of APTS development among related stakeholders, especially the responsible developers. The appropriate assessment framework is also mentioned to measure the output and outcome of the development.

Furthermore, from the response of Question 4-Question 5 which aims to enquire about forming the assessment procedure, the significance of integrated and cooperative information system and related responsibilities are highlighted. The specific responsible agency is also mentioned to perform project evaluation including publishing the evaluation report to communicate with related stakeholders. Another important factor in forming the assessment framework is a valid evaluation report with understandable measurement. Lastly, consistent communication among responsible agencies should be held to make an agreement of a common assessment framework with definite goals and objectives.

\subsection{Correlation of Fuzzy AHP and Experts' Perspective Analysis}

In consideration of fuzzy AHP and opinion responses, the assessment framework of APTS development in BMR can be represented by the important weight of each indicator. It will have a result in the priority of project proposal development to elaborate the impact and benefit of public transportation services to users of the project developer, public users and co-creation agencies. The responsible agencies should be urged to elaborate the integrated system to acquire the proposed indicators accurately.

In accordance with the FAHP weight and experts' opinion related to APTS development and assessment framework establishment, the reliability of project development is highlighted to deliver especially accurate information. It can be referred that one of the main objectives or outcomes of APTS development is to provide a trustable information system to users in order to encourage the usage of public transportation in BMR. The accurate information can also initiate the effective evaluation system and originate infor- 
mation in supporting decision-making productively. It can be also implied from the high weight in accessibility dimension weighting because the inclusive APTS system along public transportation network can provide more comprehensive information to the data analysis session.

Nonetheless, the major issue of the APTS service development in BMR is the isolated application implementation as a lack of agreement of architecture and standard resulting in a difficulty of data analysis and interpretation. The information from the system is therefore not complete and reliable for quantifying the output and outcome of system development including using it as a reference to contribute to plan and policy decisionmaking. As the weight of indicators by fuzzy AHP, the safety issue presents the most concern and demand to represent the outcome of the development. It is probably related to the difficulty of integration and collaboration across the authority not only for safety but also mobility and accessibility development on public transportation in BMR. As the responsible agencies related to public transportation in BMR are from different ministries, the indistinct and overlapping role, responsibility and regulation can cause duplicate and isolated development resulting in uncertain data analysis and information provider system development.

Another correlation between fuzzy AHP weighting and experts' opinions is the lack of concern about user perception toward APTS applications. The indicators related to users of both drivers and people obtained less weight and the responses from the expert. They also are not mentioned at the interface of applications or public surveys to give feedback of applications. The environmental perspective also earns less importance from both fuzzy AHP and opinion. It probably examines that these factors and outcomes of environmental and user preference can be a result of the effective APTS with accurate and smart information providers. Moreover, the result of the fuzzy AHP and opinion survey might represent the substantial system development to be more cooperative, composite and sustainable since the perspectives from an expert are addressed about the continued project development with a secure budget, limited knowledge and technology and maintenance management.

\section{Conclusions}

This study applied the methodology of ranking the priority of each indicator within different dimensions by fuzzy AHP, one of Multi-Criteria Decision Analysis (MDCA), since it allows us to apply the linguistic to evaluate the comparison weight of alternatives to deal with the inherent fuzziness of preference $[25,54,55]$. The hierarchy framework is developed by considering two levels of evaluation: dimension and indicators.

The result of fuzzy AHP weighting presented the ranking of indicator importance, which highlighted that safety, accessibility and mobility issue should be focused on in APTS development in BMR. In addition, to formulate the assessment framework, the integration and cooperation among stakeholders should be urged to have an agreement of the definite vision and objectives of plan deployment.

Thus, consistent with expectations regarding the fuzzy AHP weighting and experts' viewpoints, the key factors and challenges of successful APTS development and assessment framework formulation can be listed as the following:

1. It is important to eradicate the restriction of integrated and collaborated procedures of data and information among stakeholders, especially in the public and private sectors.

2. The agreement of open data platform should be brought out for discussion in order to implement, which has a result in fluent data integration implementation.

3. The appropriate central agency should be assigned to respond to an assessment of project development with legal stated roles and responsibilities while the committee or executive board can be applied to be a channel of regulation.

4. The plan and action plan should be elaborated to stakeholders with definite goals, objectives, directions, procedures, and evaluated indicators of impacts of project development under the plan. 
5. The continual project development and maintenance should be identified for a reliable and sustainable system that can serve an effective information integration and big data analysis.

6. Lastly, the service should be designed to serve users' satisfaction which leads to user participation for both planning and evaluation of the result of development.

In conclusion, consistent with expectations regarding the objectives of this study, fuzzy AHP was designed to assist the decision-maker in facilitating the prioritization of key performance indicators of APTS in BMR. The proposed indicators with weight can be further utilized in the assessment framework of APTS in BMR to trace the impact of project development from the master plan. In addition, as the fuzzy AHP method can solve the aggregation of various elements, it can be applied as a model of the key performance measurement list of each ITS section and can also be associated with project selection in accordance with indicator weights by generalizing the evaluation of performance achievement.

\section{Recommendation}

The contribution of related stakeholders is one of the major success factors in achieving the objectives of ITS development to enhance the mobility of people in the city. However, because of the limitation of communication to all dimensions of stakeholders, the number of experts from each sector can reach similar people; therefore, the result of fuzzy AHP weighting and perspectives can be investigated to compare each sector appropriately. Another limitation is the collection of indicators from the literature, which refers to indicators from other countries that have developed more advanced ITS applications than Thailand. Some indicators focus on more sustainable transportation. Although some APTS projects under the ITS master plan are related to sustainable perspectives, the project objectives cannot represent the concrete concept of sustainability.

Moreover, the proposed indicators may have mutual dependence. For example, a reduction in waiting time can have an impact on user perception, or the reduction of highpollution vehicles can reduce energy consumption and GHG emissions from the public transportation sector. Future work can apply the method to address the connection among indicators for APTS evaluation, which can be a more appropriate approach of alternative assessment for decision making.

Author Contributions: Conceptualization, A.C.; methodology, A.C.; conduct interview and formal analysis, A.C.; investigation, A.C. and C.Y.; writing-original draft preparation, A.C.; writingreview and editing, C.Y.; visualization, C.Y.; supervision, C.Y.; project administration, C.Y.; funding acquisition, C.Y. All authors have read and agreed to the published version of the manuscript.

Funding: This research was funded by the Basic Study and Interdisciplinary R\&D Foundation Fund of the University of Seoul (2021).

Institutional Review Board Statement: Not applicable.

Informed Consent Statement: Not applicable.

Conflicts of Interest: The authors declare no conflict of interest.

\section{References}

1. Shaheen, S.A.; Finson, R. Intelligent transportation systems. In Reference Module in Earth Systems and Environmental Sciences; Elsevier Encyclopedia of Energy; Elsevier: Amsterdam, The Netherlands, 2013.

2. Office Transport and Traffic Policy and Planning. Executive Summary Report: Study of Intelligent Transport System Development Master Plan in Bangkok Metropolitan Region; Office Transport and Traffic Policy and Planning: Bangkok, Thailand, 2017. 
3. Memorandum of Understanding between BMTA and ViaBus. Available online: http://www.bmta.co.th/th/content/\%E0\%B8 \%9E\%E0\%B8\%B4\%E0\%B8\%98\%E0\%B8\%B5\%E0\%B8\%A5\%E0\%B8\%87\%E0\%B8\%99\%E0\%B8\%B2\%E0\%B8\%A1\%E0\%B8\%9A \% E0\%B8\%B1\%E0\%B8\%99\%E0\%B8\%97\%E0\%B8\%B6\%E0\%B8\%81\%E0\%B8\%82\%E0\%B9\%89\%E0\%B8\%AD\%E0\%B8\%95\%E0\%B8 \%81\%E0\%B8\%A5\%E0\%B8\%87-\%E0\%B8\%84\%E0\%B8\%A7\%E0\%B8\%B2\%E0\%B8\%A1\%E0\%B8\%A3\%E0\%B9\%88\%E0\%B8\%A7 \%E0\%B8\%A1\%E0\%B8\%A1\%E0\%B8\%B7\%E0\%B8\%AD\%E0\%B8\%AA\%E0\%B8\%99\%E0\%B8\%B1\%E0\%B8\%9A\%E0\%B8\%AA\% E0\%B8\%99\%E0\%B8\%B8\%E0\%B8\%99\%E0\%B8\%81\%E0\%B8\%B2\%E0\%B8\%A3\%E0\%B9\%83\%E0\%B8\%8A\%E0\%B9\%89\%E0\%B8 $\% 87 \%$ E0\%B8\%B2\%E0\%B8\%99\%E0\%B8\%99\%E0\%B8\%A7\%E0\%B8\%B1\%E0\%B8\%95\%E0\%B8\%81\%E0\%B8\%A3\%E0\%B8\%A3 $\%$ E0\%B8\%A1-viabus-application (accessed on 6 May 2021).

4. Plan B Media. Plan B Receivs the Smart Bus Shelter Right from Bangkok, Emphasizing Being the Most Comprehensive Out of Home Media Network in the Region, Ready to Expanding Content Towards Multi-Channel Marketing. Available online: https:/ /investor.planbmedia.co.th/news.html/id/785778/group/newsroom_press (accessed on 6 May 2021).

5. Narupiti, S. Exploring the possibility of MaaS service in Thailand, implications from the existing conditions and experts' opinions on "Who should be the MaaS provider in Bangkok?" IATSS Res. 2019, 43, 226-234. [CrossRef]

6. Office Transport and Traffic Policy and Planning. Evaluation Report of ITS Action Plan Short Term (3 Years: 2018-2020); Office Transport and Traffic Policy and Planning: Bangkok, Thailand, 2020.

7. Antolin, J.; Torre, C.D.; Garcia-Fuentes, M.A.; Perez, A.; Tome, I.; Mirantes, M.L.; Hoyos, E. Development of an evaluation framework for smartness and sustainability in cities. Sustainability 2020, 12, 5193. [CrossRef]

8. Newman-Askins, R.; Ferreira, L.; Bunker, J. Intelligent Transport System Evaluation: From theory to practice. In Proceedings of the 21st ARRB and 11th REAAA Conference, Cairns, QLD, Australia, 18-23 May 2003; Cairns, Australia, Jaeger, V., Ed.;

9. Ishizaka, A.; Labib, A. Review of the main developments in the Analytic Hierarchy Process. Expert Syst. Appl. 2011, 38, 14336-14345. [CrossRef]

10. Chen, L.; Deng, X.A. Modified method for evaluating sustainable transport solutions based on AHP and Dempster-Shafer Evidence Theory. Appl. Sci. 2018, 8, 563. [CrossRef]

11. Vaidya, O.; Kumar, S. Analytic Hierarchy Process: An overview of applications. Eur. J. Oper. Res. 2006, 169, 1-29. [CrossRef]

12. Yeh, C.H.; Deng, H.; Chang, Y.H. Fuzzy multicriteria analysis for performance evaluation of bus companies. Eur. J. Oper. Res. 2000, 126, 59-473. [CrossRef]

13. Pedrycz, W.; Ekel, P.; Parreiras, R. Fuzzy Multicriteria Decision-Making: Model, Methods and Applications; John Wiley \& Sons: Hoboken, NJ, USA, 2010; pp. 14-17.

14. Kabir, G.; Hasin, M.A.A. Comparative analysis of AHP and fuzzy AHP models for multicriteria inventory classification. Int. J. Fuzzy Log. Syst. 2011, 1, 1-16.

15. Kolosz, A.W.; Grant-Muller, A. Appraisal and evaluation of interurban ITS: A European survey. IEEE Trans. Intell. Transp. Syst. 2014, 16, 1070-1087. [CrossRef]

16. Advanced Public Transportation Systems: Evaluation Guidelines. Available online: https://rosap.ntl.bts.gov/view/dot/5479 /dot_5479_DS1.pdf? (accessed on 18 March 2021).

17. Guideline for Developing and Maintaining for Sustainable Urban Mobility, Second Edition. Available online: https://www.eltis. org/mobility-plans/sump-online-guidelines (accessed on 16 December 2021).

18. Bae, S. An advanced public transportation system application: Feasibility study of bus passenger information systems operational test in the town of Blacksburg. In Proceedings of the 1995 Vehicle Navigation and Information Systems Conference, 6th International VNIS. A Ride into the Future, Seattle, WA, USA, 30 July-2 August 1995; pp. 408-413.

19. Piao, J.; McDonald, M.; Henry, A.; Vaa, T.; Tviet, Ø. An assessment of user acceptance of intelligent speed adaption systems. In Proceedings of the 8th International IEEE Conference on Intelligent Transportation Systems, Vienna, Austria, 13-16 September 2005.

20. Rafiyan, E. Acceptability of Intelligent Transportation System (ITS) to Various Group of Drivers. Master's Thesis, University of Gothenburg, Gothenburg, Sweden, May 2013.

21. Hassn, H.A.A.; Ismail, A.; Borhan, M.N.; Syamsunur, D. The impact of Intelligent Transport System quality: Drivers' acceptance perspective. Int. J. Technol. 2016, 4, 553-561. [CrossRef]

22. Jeong, H.S. A Study on the Effect Analysis System According to the Introduction of Advanced Traffic Management System (ATMS). Master's Thesis, Kongju National University, Chungcheongnam-do, Korea, 24 February 2021; pp. 64-65.

23. Yang, L.; Dam, K.H.; Zhang, L. Developing goals and indicators for the design of sustainable and integrated transport infrastructure and urban spaces. Sustainability 2020, 12, 9677. [CrossRef]

24. Guerrero-Ibáñez, J.; Zeadally, S.; Contreras-Castillo, J. Sensor Technologies for Intelligent Transportation Systems. Sensors 2018, 18, 1212. [CrossRef] [PubMed]

25. Fedele, R.; Praticò, F.G. Monitoring infrastructure asset through its acoustic signature. In Proceedings of the Internoise 2019, Marid, Spain, 16-19 June 2019.

26. Dobranskyte-Niskota, A.; Perujo, A.; Jesinghaus, J.; Jensen, P. Indicators to Assess Sustainability of Transport Activities-Part 2: Measurement and Evaluation of Transport Sustainability Performance in the EU27. EUR 23041 EN/2; European Commission: Luxembourg, 2009.

27. Shiau, T.A.; Liu, J.S. Developing an indicators system for local government to evaluate transport sustainability strategies. Ecol. Indic. 2013, 34, 361-371. [CrossRef]

28. Niglio, R.; Comitale, P.P. Cities, energy and built environment. TeMA J. Land Use Mobil. Environ. 2015, 8. [CrossRef] 
29. Mitropoulos, K.L.; Prevedouros, P.D. Incorporating sustainability assessment in transportation planning: An urban transportation vehicle-based approach. Transp. Plan. Technol. 2016, 39, 439-463. [CrossRef]

30. Wengler, M. Mobility as a Service (MaaS) as an Instrument for Transport Policy. Master's Thesis, Vienna University of Technology, Vienna, Austria, 8 May 2017.

31. Chen, C.T.; Lin, C.T.; Huang, S.F. A fuzzy approach for supplier evaluation and selection in supply chain management. Int. J. Prod. Econ. 2005, 102, 289-301. [CrossRef]

32. Lopez-Carreiro, I.; Monzon, A. Evaluating sustainability and innovation of mobility patterns in Spanish cities. Analysis by size and urban typology. Sustain. Cities Soc. 2018, 38, 684-696. [CrossRef]

33. Environmental Equity Mobility Equity Framework: How to Make Transport Work for People. Available online: https:// greenlining.org/wp-content/uploads/2018/03/Mobility-Equity-Framework-Final.pdf (accessed on 3 May 2021).

34. Zapolskyte, S.; Burinskiene, M.; Trepanier, M. Evaluation criteria of smart city mobility system using MCDM method. Balt. J. Road Bridge Eng. 2020, 15, 196-224. [CrossRef]

35. Othaman, M.; Ku-Mahamud, K.R. Fuzzy multi criteria evaluation for performance of bus companies. Comput. Inf. Sci. 2010, 3 , 252-262. [CrossRef]

36. Suwardo. Assessment of Bus System Service and Performance for Public Transport Improvement. Ph.D. Thesis, University of Teknologi Petronas, Perak, Malaysia, August 2010.

37. Ambrosino, G.; Finn, B.; Gini, S.; Mussone, L. A method to assess and plan applications of ITS technology in public transport services with reference to some possible case study. Case Stud. Transp. Policy 2015, 3, 421-430. [CrossRef]

38. Lee, D.J. A multi-criteria approach for prioritizing advanced public transport modes (APTM) considering urban type in Korea. Transp. Res. Part A Policy Pract. 2018, 111, 148-161. [CrossRef]

39. Longo, A.; Zappatore, M.; Navathe, S.B. The unified chart of mobility services: Towards a systemic approach to analyze service quality in smart mobility ecosystem. J. Parallel Distrib. Comput. 2019, 127, 118-133. [CrossRef]

40. Levine, J.; Underwood, S.E. A multiattribute analysis of goals for Intelligent Transportation System planning. Transp. Res. Part C Emerg. Technol. 1996, 4, 97-111. [CrossRef]

41. Evaluating Intelligent Transportation System Impacts: A Framework for Border Analyses. Available online: https://static.tti. tamu.edu/tti.tamu.edu/documents/TTI-2000-ID15289.pdf (accessed on 28 March 2021).

42. Hanaoka, S.; Kunadhamraks, P. Multiple criteria and fuzzy based evaluation of logistics performance for intermodal transportation. J. Adv. Transp. 2008, 43, 123-153. [CrossRef]

43. Zou, L.; Dai, H.; Yao, E.; Jiang, T.; Gou, H. Research on assessment methods for urban public transport development in China. Comput. Intell. Neurosci. 2014, 2014, 941347. [CrossRef] [PubMed]

44. Final Report of the Study on Key Performance Indicators for Intelligent Transport System. Available online: https: / / ec.europa. eu/transport/sites/default/files/themes/its/studies/doc/its-kpi-final_report_v7_4.pdf (accessed on 21 April 2021).

45. Verseckiene, A.; Palsaitis, R.; Yatskiv, I. Evaluation of alternatives to integrate special transportation service for people with movement disorders. Transp. Telecommun. 2017, 18, 263-274. [CrossRef]

46. CITY Keys Indicators for Smart City Projects and Smart Cities. Available online: https://nws.eurocities.eu/MediaShell/media/ CITYkeystheindicators.pdf (accessed on 20 April 2021).

47. Krmac, E.; Djordjevic, B. An evaluation of train control information systems for sustainable railway using the Analytic Hierarchy Process (AHP) model. Eur. Transp. Res. Rev. 2017, 9, 35. [CrossRef]

48. Krmac, E.; Djordjevic, B. An evaluation of indicators of railway intelligent transportation system using the Group Analytic Hierarchy Process. Electron. Sci. Technol. Appl. 2017, 4. [CrossRef]

49. Garau, C.; Pavan, V.M. Evaluating urban quality: Indicators and assessment tools for smart sustainable cities. Sustainability 2017, 10, 575. [CrossRef]

50. Mlinaric, T.J.; Djordjvevic, B.; Krmac, E. Evaluation framework for key performance indicators of railway ITS. Promet-Traffic Transp. 2018, 30, 491-500. [CrossRef]

51. Weng, J.; Di, X.; Wang, C.; Wang, J.; Mao, L. A bus service vvaluation method from passenger's perspective based on satisfaction survey: A case study of Beijing, China. Sustainability 2018, 10, 2723. [CrossRef]

52. Cyril, A.; Mulangi, R.H.; George, V. Performance optimization of public transport using Integrated AHP-GP methodology. Urban Rail Transit 2019, 5, 133-144. [CrossRef]

53. Buenk, R.; Grobbelaar, S.S.; Meyer, I. A framework for the sustainability assessment of (micro)transis systems. Sustainability 2019, 11, 5929. [CrossRef]

54. Chao, A.L.; Gallego, A.C.; Lopez-Chao, V. Indicators framework for sustainable urban design. Atmosphere 2020, 11, 1143. [CrossRef]

55. Chan, W.C.; Ibrahim, W.H.W.; Lo, M.C.; Suaidi, M.K.; Ha, S.T. Sustainability of public transportation: An examination of user behavior to real-time GPS tracking application. Sustainability 2020, 12, 9541. [CrossRef]

56. Brucker, K.; Verbeke, A.; Macharis, C. The applicability of multicriteria-analysis to the evaluation of Intelligent Transport System (ITS). Res. Transp. Econ. 2004, 8, 151-179. [CrossRef]

57. Ishizaka, A.; Nemery, P. Multi-Criteria Decision Analysis: Method and Software; Jonh Wiley \& Sons, Ltd.: Hoboken, NJ, USA, 2013; pp. 5-7. 
58. Saaty, T.L. Fundamentals of Decision Making and Priority Theory with the Analytic Hierarchy Process; RWS Publications: Pittsburgh, PA, USA, 2001; pp. 5-9, 95.

59. Chang, D.Y. Applications of the extent analysis method on fuzzy AHP. Eur. J. Oper. Res. 1996, 95, 649-655. [CrossRef]

60. Lee, S.L.; Chen, P.C.; Chan, W.C.; Hung, S.W. A three-stage decision-making model for selecting electric vehicle battery technology. Transp. Plan. Technol. 2015, 38, 761-776. [CrossRef]

61. Oguztimur, S. Why Fuzzy Analytic Hierarchy Process approach for transport problem? In Proceedings of the 51st Congress of the European Regional Science Association: "New Challenges for European Regions and Urban Areas in a Globalised World", Barcelona, Spain, 30 August-3 September 2011.

62. Nalmpantis, D.; Roukouni, A.; Genitsaris, E.; Stamelou, A.; Naniopoulos, A. Evaluation of innovative ideas for public open access transport proposed by citizens using Multi-criteria decision analysis (MCDA). Eur. Transp. Res. Rev. 2019, 11, 22. [CrossRef]

63. Salavati, A.; Haghshenas, H.; Ghadirifaraz, B.; Jamshid Laghaei, J.; Eftekhari, G. Applying AHP and clustering approaches for public transportation decision making: A Case Study of Isfahan City. J. Public Transp. 2016, 19, 38-55. [CrossRef]

64. Janackovic, G.L.; Savic, S.M.; Stankovic, M.S. Selection and ranking of occupational Safety indicators based on Fuzzy AHP: A case study in road construction companies. South Afr. J. Ind. Eng. 2013, 24, 175-189. [CrossRef]

65. Wibowo, S.; Grandhi, S. A multicriteria analysis approach for benchmarking smart transport cities. In Proceedings of the Science and Information Conference 2015, London, UK, 28 July 2015.

66. Milosevic, D.; Stanojevic, A.; Milosevic, M. AHP method in the function of logistic in development of smart cities model. In Proceedings of the 6th International Conference: Transport and Logistic, Niš, Serbia, 25-26 May 2017; pp. 287-294.

67. Ananda, A.; Rufuss, D.D.W.; Rajkumara, V.; Suganthi, L. Evaluation of sustainability indicators in smart cities for India Using MCDM approach. Energy Procedia 2017, 141, 211-215. [CrossRef]

68. Firouzabadi, S.M.A.K.; Henson, B.; Barnes, C. A multiple stakeholders' approach to strategic selection decisions. Comput. Ind. Eng. 2008, 54, 851-865. [CrossRef]

69. Li, X.; Fan, Y.; Shaw, J.W.; Qi, Y. A Fuzzy AHP approach to compare transit system performance in US urbanized areas. J. Public Transp. 2017, 20, 66-89. [CrossRef]

70. Wang, X.; Ma, X.; Fan, J.; Ye, Q. Design of intelligent logistics drivers evaluation system-based on entropy-AHP method. In Proceedings of the 16th International Conference on Service Systems and Service Management (ICSSSM), Shenzhen, China, 13-15 July 2019; pp. 1-6.

71. Hamurcu, M.; Eren, T. Strategic planning based on sustainability for urban transportation: An application to decision-making. Sustainability 2020, 12, 3589. [CrossRef]

72. Kwong, C.K.; Bai, H. Determining the importance weights for the customer requirements in QFD using a fuzzy AHP with an extent analysis approach. IIE Trans. 2003, 35, 619-626. [CrossRef]

73. Buckley, J.J. Fuzzy hierarchical analysis. Fuzzy Sets Syst. 1985, 17, 233-247. [CrossRef] 